\title{
Article \\ Carbon Nanotubes Transform Soft Gellan Gum Hydrogels into Hybrid Organic-Inorganic Coatings with Excellent Cell Growth Capability
}

\author{
Anatolii Abalymov 1,2,3, Louis Van der Meeren ${ }^{1}$ D, Dmitry Volodkin $4\left(\mathbb{D}\right.$, Bogdan Parakhonskiy ${ }^{1, *(D)}$ \\ and Andre G. Skirtach 1,*(D) \\ 1 Department of Biotechnology, Ghent University, 9000 Ghent, Belgium; anatolii.abalymov@ugent.be (A.A.); \\ louis.vandermeeren@ugent.be (L.V.d.M.) \\ 2 Remote Controlled Theranostic Systems Lab, Educational Research Institute of Nanostructures and \\ Biosystems, Saratov State University, 410012 Saratov, Russia \\ 3 Center for Photonics and Quantum Materials, Skolkovo Institute of Science and Technology, \\ 121205 Moscow, Russia \\ 4 School of Science and Technology, Nottingham Trent University, Clifton Lane, Nottingham NG11 8NS, UK; \\ dmitry.volodkin@ntu.ac.uk \\ * Correspondence: Bogdan.Parakhonskiy@UGent.be (B.P.); Andre.Skirtach@UGent.be (A.G.S.)
}

check for updates

Citation: Abalymov, A.; Van der

Meeren, L.; Volodkin, D.;

Parakhonskiy, B.; Skirtach, A.G. Carbon Nanotubes Transform Soft Gellan Gum Hydrogels into Hybrid Organic-Inorganic Coatings with Excellent Cell Growth Capability. C 2021, 7, 18. https://doi.org/10.3390/ c7010018

Received: 16 December 2020

Accepted: 30 January 2021

Published: 4 February 2021

Publisher's Note: MDPI stays neutral with regard to jurisdictional claims in published maps and institutional affiliations.

Copyright: (c) 2021 by the authors. Licensee MDPI, Basel, Switzerland. This article is an open access article distributed under the terms and conditions of the Creative Commons Attribution (CC BY) license (https:// creativecommons.org/licenses/by/ $4.0 /)$.
Abstract: Carbone nanotubes (CNTs) possess distinct properties, for example, hardness, which is very complementary to biologically relevant soft polymeric and protein materials. Combining CNTs with bio-interfaces leads to obtaining new materials with advanced properties. In this work, we have designed novel organic-inorganic hybrid coatings by combining CNTs with gellan gum (GG) hydrogels. The surface topography of the samples is investigated using scanning electron microscopy and atomic force microscopy. Mechanical properties of synthesized hybrid materials are both assessed at the macro-scale and mapped at the nanoscale. A clear correlation between the CNT concentration and the hardness of the coatings is revealed. Cell culture studies show that effective cell growth is achieved at the CNT concentration of $15 \mathrm{mg} / \mathrm{mL}$. The presented materials can open new perspectives for hybrid bio-interfaces and can serve as a platform for advanced cell culture.

Keywords: carbon nanotubes; hydrogels; gellan gum; AFM; mechanical properties; cells

\section{Introduction}

Hydrogels are very attractive materials for biomedical applications-they can be composed of biologically relevant and biocompatible polymers. Their physico-chemical properties can be controlled and hydrogels have large amounts of water that can work as space to host molecules of interest. Hydrogels can be used for encapsulation of biologicallyrelevant materials, to form injectable forms [1,2], as bone defect fillers, for surface functionalization via coating and formation of 3D gel matrices which can support tissue and organ engineering, i.e., bioprinting [3].

The injectable materials approach means that outside of the body, the material is liquid but solidifies in situ. Thereby, the defect is filled since the injected material can adopt the shape and size of a defect. This way, introduction is minimally invasive causing lesser discomfort for a patient [4]. Such injectable hydrogels can be built based on proteins and polysaccharides [5]. In addition, bone filling materials often include bone cement consisting of calcium phosphates [6]. Hydrogel surface functionalization or bioprinting provides a special biocoating that could serve as a 2D or 3D template for cell adhesion [7], align cells [8], or encapsulate and release functional biomolecules like alkaline phosphatase [9]. Various polymers can be used to construct hydrogels for tissue engineering [10]. However, a more interesting approach is using polymers with ionic cross-linkage mechanisms, like alginate 
and gellan gum, due to easy control of gelation and a chemically "mild" method of gel preparation.

Various approaches have been developed to overcome the mechanical weakness of hydrogels, for example, crosslinking. However, this includes the use of chemical agents. Hybrid materials and interfaces [11] represent an attractive alternative to chemical crosslinking and have been applied in various nanomedicine $[12,13]$ applications. For example, nanoparticles [14] have been identified as key enabling components for the construction of robust polymeric coatings with advanced functionalities including, for example, laser activation [15]. Carbone nanotubes (CNTs) represent a special class of carbon-based materials; they have been used for different applications including supercapacitors, photovoltaics, photodiodes, sensors [16]. Indeed, adding carbon-based structures offers advantages because unique properties of carbon materials such as high conductivity, robustness, possibilities of biochip functionalization can be used [17]. Earlier, it was reported that CNTs enhance the mechanical properties of freely suspended polymeric microcapsules [18].

A wide range of applications in biomedicine has also been identified for materials based on CNTs and hydrogels including tissue engineering, drug delivery, theranostics, sensing, and biosensing [19-21]. However, dispersing carbon-based structures represents a particular challenge. With regard to this, oxidation plays an important role [22]. The following acid solutions have been often used for oxidation of CNTs: $\mathrm{HNO}_{3}$ [23], $\mathrm{KMnO} / \mathrm{H}_{2} \mathrm{SO}_{4}$ [24]. In the oxidation, thermal processes were identified as an essential constituent [25]. However, the possibility of using particularly loose and stand-alone nanotube for bioapplication may be hazardous, which requires additional research [26].

The low tensile strength of many hydrogels limits their use for effective cell growth. Several strategies are available to increase the mechanical strength of the hydrogel. For example, it is possible to design hybrid materials [11] by incorporating various particles or networks [27], for example, microcapsules [28], bioglass particles [29], hydroxyapatite particles [30,31] calcium, and magnesium carbonate particles [32-35]. In this case, it is identified that the cell senses the environment and literally "grabs" hard particles at surfaces [33]. An overview of various interfaces allows us to conclude that many particles incorporated into polymeric coatings can promote cell adhesion [36-38]. Carbon-based structures represent interesting alternatives for the functionalization of polymeric surfaces, but their full potential remains to be explored in more detail.

In this work, we demonstrate that adding CNTs to rather soft gellan gum (GG) hydrogels transforms these cell "unfriendly" (repelling) coatings into a very effective cell culture platform. Analysis of the mesh sizes and structure of such hybrid coatings is performed using scanning electron microscopy (SEM) and atomic force microscopy (AFM). Also, mechanical properties of CNT-GG hydrogels are investigated at both macro- and nano-scales revealing that the addition of CNTs results in the formation of very robust and mechanically stiff coatings. Implications for cell culture growth is also discussed here. The most essential parameter enabling effective cell growth on soft hydrogel structuresthe minimum CNT concentration-have been identified.

\section{Materials and Methods}

\subsection{Hydrogel Synthesis}

GG hydrogels with loaded CNTs (GG-CNTs) were formed by mixing various concentrations $0.5,1$ and $1.5 \% \mathrm{w} / \mathrm{v}(5,10$, and $15 \mathrm{mg} / \mathrm{mL})$ of CNTs (Sigma-Aldrich, can. No. $677248-5 \mathrm{G})$ with $1 \% \mathrm{w} / \mathrm{v}(10 \mathrm{mg} / \mathrm{mL}$ ) Gelzan (GG CM, product no. G1910, "Low-Acyl", 200-300 kDa) [39]. Solutions were mixed by vortex for 5 min and US bath (Digital 10 P, Bandelin SONOREX, Germany) at HF-Frequency $35 \mathrm{kHz}$ for $15 \mathrm{~min}$ at room temperature. After that GG-CNTs solution was crosslinked by $\mathrm{CaCl}_{2}(0.3 \mathrm{M})$ for $20 \mathrm{~min}$. After this step, hydrogels are washed twice with water to remove unreacted ions. 


\subsection{Scanning Electron Microscopy}

GG-CNTs hydrogels were characterized by scanning electron microscopy (SEM). Hydrogel cylinders with $5 \mathrm{~mm}$ diameter were cut by biopsy and transferred to an aluminum stage covered with double-sided carbon tape. Before SEM, the hydrogels were dried by a lyophilizer and coated with a $15 \mathrm{~nm}$ thick gold layer (Bal-tec SCD050 Sputter Coater, MA, USA). The measurement was performed with JSM-T330A from JEOL at the operating voltage of $25 \mathrm{kV}$ with secondary electrons.

\subsection{Mechanical Tests Using a Universal Testing Machine}

Mechanical stiffness of gels has been performed using a Universal Test Machine, LS1 $(1 \mathrm{kN})$ Material Tester from Lloyd Instruments, Inc. (Ametek, PA, USA). A $50 \mathrm{~N}$ load cell was used for making a $2 \mathrm{~mm}$ indentation in samples with the diameter of the tip of $10 \mathrm{~mm}$ (the preload was set to $0.05 \mathrm{~N}$ ).

\subsection{Atomic Force Microscopy}

The AFM data were acquired using a Nanowizard 4 Atomic Force Microscope (Bruker/JPK Instruments, Berlin, Germany) operated in the quantitative imaging (QI) mode (in liquid). All maps were obtained with QP-BioAC - CI probes (Nanosensors, Neuchatel, Switzerland), using the cantilever which had a nominal frequency of $50 \mathrm{kHz}$ and a force constant of $0.1 \mathrm{~N} / \mathrm{m}$ (calibrated in contact-free mode). Force maps were collected using a set point of $3 \mathrm{nN}$ at $1.6 \mathrm{~ms}$ per pixel, with a $\mathrm{Z}$ length of $0.2 \mu \mathrm{m}$ and a tip speed of $125 \mu \mathrm{m} / \mathrm{s}$. The force and height maps were $25 \mu \mathrm{m} \times 25 \mu \mathrm{m}$. To measure mechanical and topographical properties, AFM was utilized with the DNP-s10 cantilever (Bruker, MA, USA).

\subsection{Microrheology}

To gain information on the viscoelastic properties of hydrogels, microrheological measurements were performed using DNP-S10 chips (nominal frequency of $50 \mathrm{kHz}$ and a force constant of $0.1 \mathrm{~N} / \mathrm{m}$ ). In these measurements, the force reaction toward small amplitude oscillating forces (at low frequencies) that are applied at the surface are analyzed. The oscillations in the experiments were performed with an amplitude of $50 \mathrm{~nm}$ at frequencies ranging between 10 and $200 \mathrm{~Hz}$ (in the following steps: 10, 20, 50, 75, 100, $150,200 \mathrm{~Hz}$ ). Calculations of the storage and the loss moduli were performed in JPK data processing software, based on calculations adapted from a previous paper on microrheological measurements on live cells [40]. To accommodate for influences originating from the cantilever's geometry, first, the deviation from $90^{\circ}$ phase shift in the liquid environment and the hydrodynamic drag coefficient was calculated and incorporated into the measurements. Fitting the microrheological data to the soft glassy rheology model was performed by non-linear fitting in OriginPRO 2020 [41].

\subsection{Osteoblasts Cultivation}

Osteoblastic MC3T3-E1 cells were cultured in MEM-alpha glutaMAX-1 (cat. no. 32561029) supplemented with $10 \% \mathrm{FBS}$, and $100 \mu \mathrm{g} / \mathrm{mL}$ penicillin/streptomycin. The media were replaced every three days, and the cells were maintained in a humidified incubator at $5 \% \mathrm{CO}_{2}$ and $37^{\circ} \mathrm{C}$ (Innova CO-170, New Brunswick Scientific, NJ, USA).

\subsection{Fluorescence Microscopy}

To estimate cell adhesion and proliferation on the surface of the prepared samples, viable cells were visualized by a fluorescence microscope using a microscope Nikon TI (Nikon, Japan) with Objective 10 $\times$ and appropriate filters. MC3T3-E1 cells were seeded on the sample surfaces with an area of $0.31 \mathrm{~cm}^{2}$ at a cell density of $10 \times 10^{3} /$ sample and incubated for 1 and 3 days. Afterward, cells were stained with Calcein AM. Samples were washed two times in PBS to remove the non-adhered cells. The number of cells was calculated from snapshots of three random zones for three replicates of the samples. 


\subsection{Cell Viability Test}

The effects of samples on MC3T3-E1 cells were determined by AlamarBlue (ThermoFisher Scientific; Cat. No DAL1025). Samples were lowered to the bottom of a 96-well plate. MC3T3-E1 cells were seeded into 96-well on hydrogel samples at a cell density of $10 \times 10^{3} /$ well in the culture medium and incubated 1 and 3 days at $37^{\circ} \mathrm{C}$ under $5 \% \mathrm{CO}_{2}$. In the last step, $10 \mu \mathrm{L}$ of fluorescence dye (AlamarBlue) was added to each well, and the fluorescent $(540 / 610 \mathrm{~nm})$ intensity was measured by a spectrophotometer (Infinite F200 PRO, Tecan, Switzerland).

\section{Results}

\subsection{Fabrication of GG-CNTs Hydrogels}

The GG-CNTs hydrogels were produced by the following method: the GG solution $(10 \mathrm{mg} / \mathrm{mL}$ ) was deposited into the $15 \mathrm{~mL}$ falcon tube, then CNTs (SEM image of CNTs present on Figure S1 were added in the falcon tube in concertation 5, 10, and $15 \mathrm{mg} / \mathrm{mL}$ (Figure 1). To obtain a better distribution of CNTs in GG solution vortex and US-bath were used; afterward, the GG-CNTs solutions were cross-linked in the presence of calcium ions (supplied by a $0.33 \mathrm{M}$ solution of $\mathrm{CaCl}_{2}$ ).

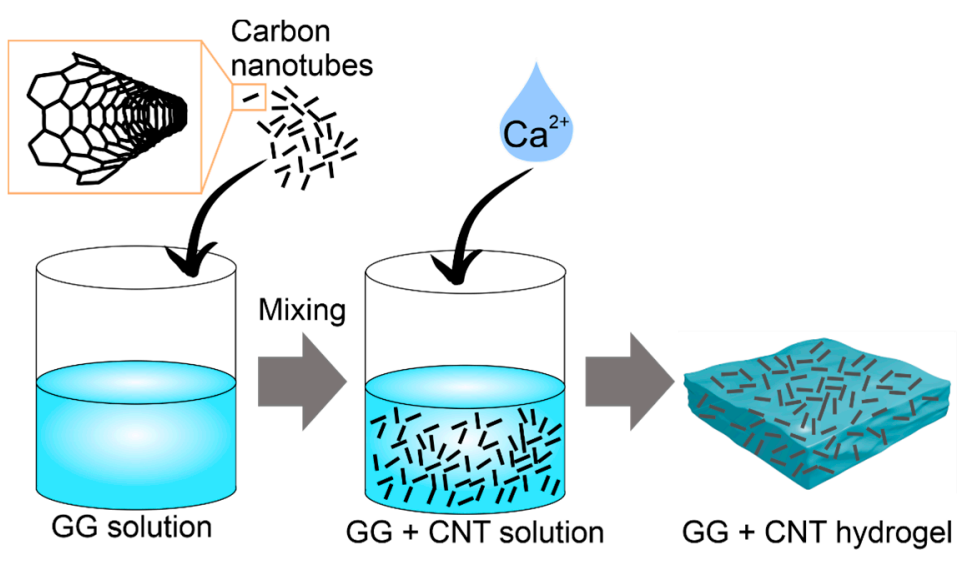

Figure 1. Schematic of the synthesis of gellan gum (GG)-carbon nanotubes (CNTs) hydrogel hybrid surfaces. The added carbon nanotubes are depicted as dark rods, while the GG solution is light blue at the beginning (left) but turns into harder hydrogel (right).

\subsection{Hydrogels Morphology and Structure Characterization}

Macro image of all types of hydrogels can be seen in Figure S2b. The morphology of GG-CNTs hydrogels was studied using AFM and SEM (Figure 2a-c). CNTs concertation has a significant influence on hydrogel architecture. Particularly the mesh size decreased with increasing the concentration of CNTs in hydrogels (Figure 2b) from $180 \pm 8$ (SE) nm for pure GG to $85 \pm 2 \mathrm{~nm}$ for gels prepared using $15 \mathrm{mg} / \mathrm{mL}$ CNT solution. As shown in a box chart, the dispersity of the mesh size decreases as well, which proves that the hydrogel with a higher concentration of CNT has a more regular structure. SEM images of the hydrogels revealed comparable high roughness on the GG-CNTs surface for samples prepared using CNTs of 5, 10, and $15 \mathrm{mg} / \mathrm{mL}$, which is higher than that for control GG. This can be associated with the presence of CNTs conglomerates on the gel-mesh surface. To prove the presence of the CNTs inside hydrogels, we have conducted experiments with light absorbance by spectroscopy (Figure S2a), where a clear increase in adsorption is seen depending on the amount of CHTs in the hydrogels. 


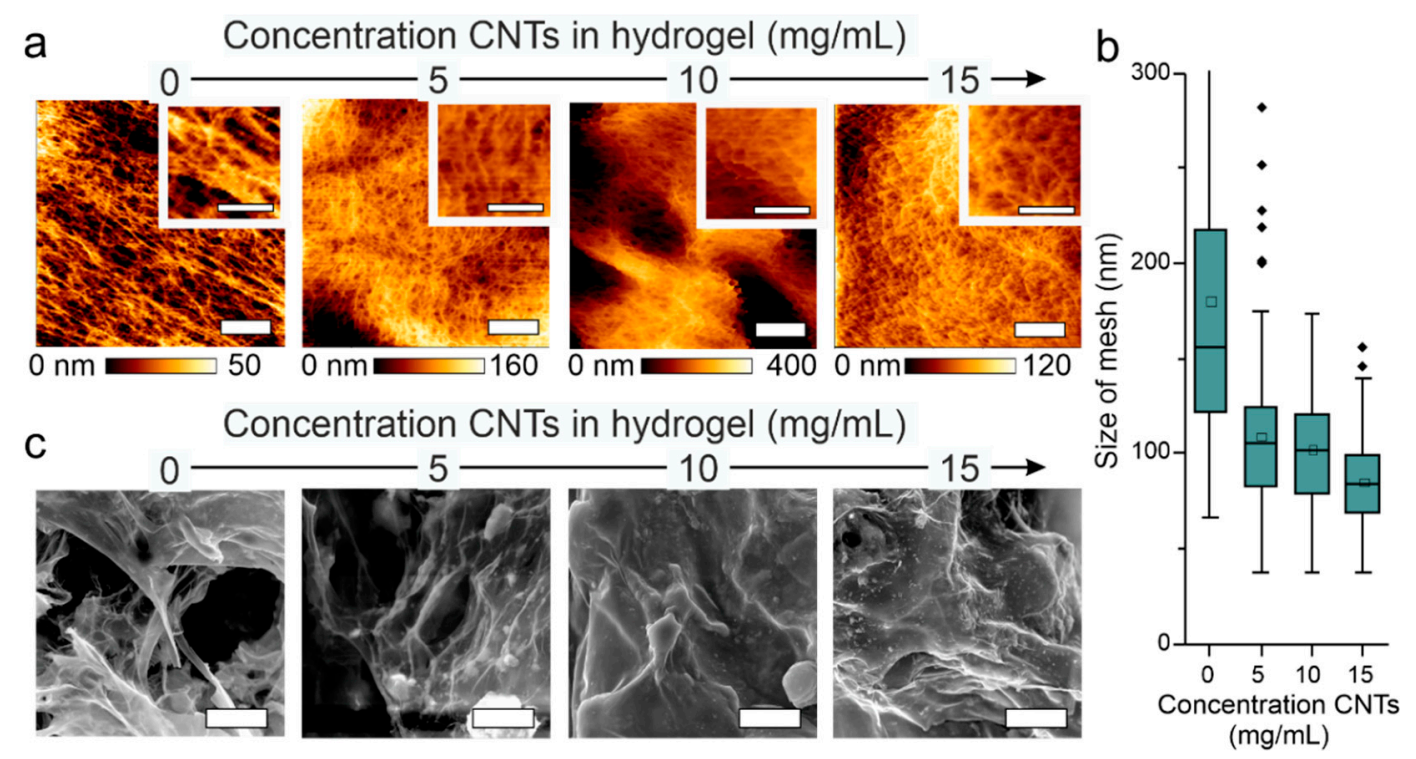

Figure 2. (a) Topography (height) mapping of the surface of GG-CNTs hydrogels obtained by atomic force microscopy (AFM). The scale bars are $1 \mu \mathrm{m}$; scale bars in insertion are $0.5 \mu \mathrm{m}$. (b) Size of the mesh of GG-CNTs hydrogels. (c) SEM images of the surface of GG-CNTs hydrogels. The scale bar is $50 \mu \mathrm{m}$.

The degree of swelling of hydrogels was also investigated (Figure S3). A statistical difference between the degree of swelling of the hydrogels is observed between the 0 and $15 \mathrm{mg} / \mathrm{mL}$ samples. This shows that high concentrations of CNTs reduce the degree of swelling of hydrogels.

\subsection{Macro- and Nano-Mechanical Properties of the Hydrogels}

The influence of the mesh size and concentration of CNTs in hydrogels on Macro Mechanical Properties (MMP) and Nano Mechanical Properties (NMP) was investigated by compression tests using an Universal Testing Machine (UTM) (Figure 3a). As it can be seen from this schematic, using a UTM, we have measured the rigidity of the entire hydrogel completely, which gives us an idea of the behavior of the material in tissues under various loads. Using AFM, we evaluated the surface and stiffness of the hydrogel at the nanoscale, where we can distinguish between individual fibrils and hydrogel particles, thanks to this, we can assume the interaction of cells with the sample surface. Stress/strain curves were obtained by the UTM for $50 \%$ of the deformation of hydrogels. Although one would expect an altered mechanical behavior of the hydrogel after the addition of a low concentration of CNTs ( 5 and $10 \mathrm{mg} / \mathrm{mL}$ ), the stress-strain curves for GG-CNTs composite materials were similar and their compressive moduli were not significantly different (Figure 3b). In contrast, the compressive modulus of the sample prepared with $15 \mathrm{mg} / \mathrm{mL}$ CNTs was significantly lower than that for hydrogels with lower CNT concentrations. Such mechanical behavior can be explained by the incorporation of CNTs into the hydrogel mesh that violates the integrity of polymer compounds. Figure $3 \mathrm{c}$ demonstrates the process of hydrogels compressing during the test. 

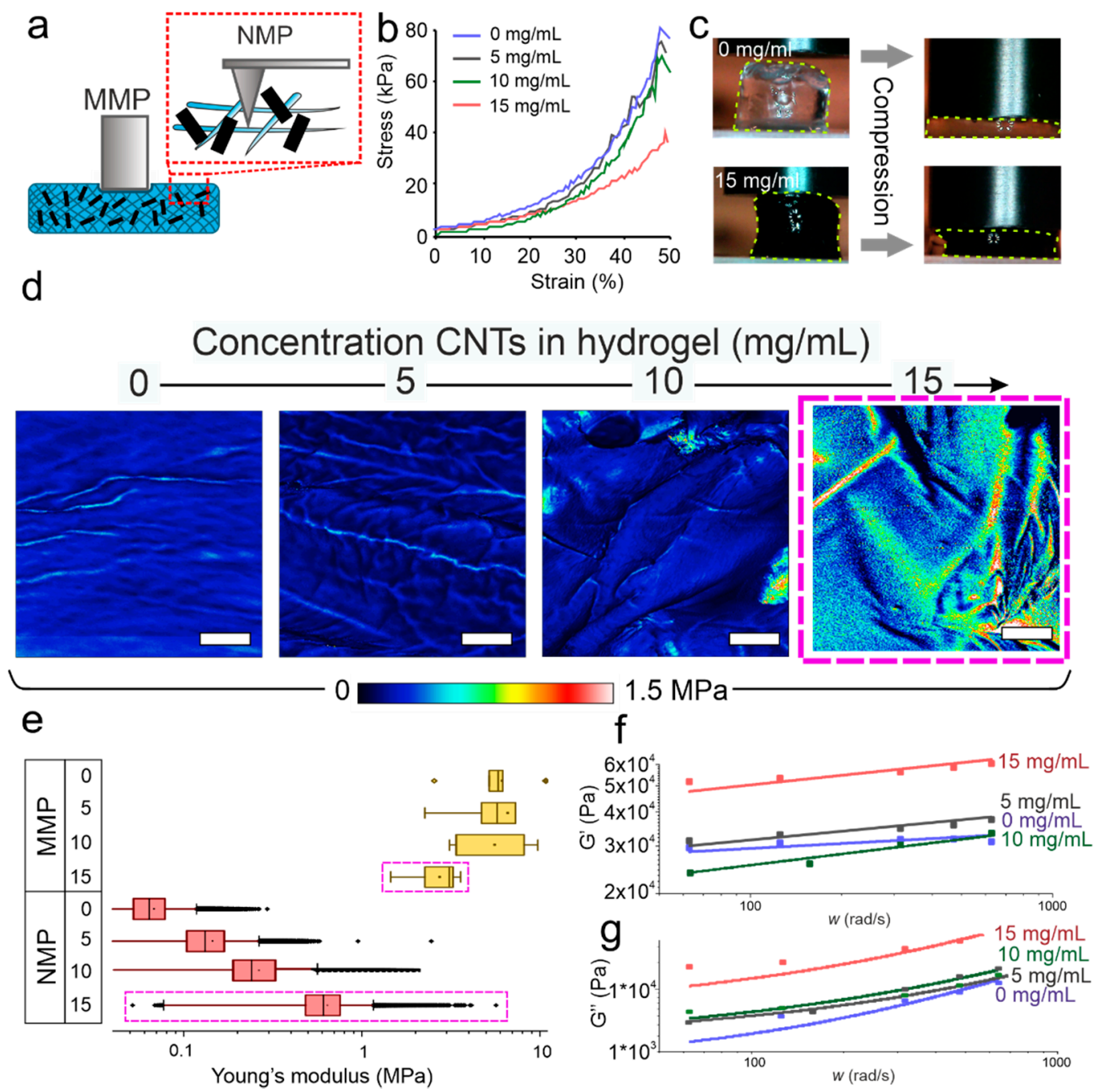

Figure 3. (a) Schematic representation of Macro Mechanical Properties (MMP) and Nano Mechanical Properties (NMP) measurements. (b) Stress/strain curves obtained by an Universal Testing Machine (UTM). (c) Images of the compression process of GG-CNTs hydrogels. (d) Force mapping of the surface of GG-CNTs hydrogels obtained by AFM. The scale bar is $5 \mu \mathrm{m}$ (the scale bar is $4 \mu \mathrm{m}$ ). (e) The Young's modulus values for GG-CNTs obtained using UTM (10 mm tip) and AFM. The relative standard error for AFM measurements is less than 1\%. (f) The storage modulus of GG-CNTs hydrogels as a function of frequency. (g) The loss modulus of GG-CNTs hydrogels as a function of frequency.

As a result of NMP characterization, the mapping of mechanical properties of the surface of hydrogels was carried out by AFM (Figure 3d). However, NMP of hydrogel with $15 \mathrm{mg} / \mathrm{mL}$ CNTs showed the best results, which can be seen from the figure, there all maps have the same force scale (0-1.5 MPa) (Figure 3d, purple frame). Force maps look dark blue, which indicates a low Young's modulus compared to the sample prepared using $15 \mathrm{mg} / \mathrm{mL}$ CNTs solution. This result indicates the obvious presence on the hydrogel surface of rigid CNTs on the hydrogel with the concentration of $15 \mathrm{mg} / \mathrm{mL}$. Concentrations below this value are not sufficient to obtain similar mechanical properties of hydrogel surfaces. For a better understanding of the difference between the MMP and the NMP, a graph was constructed comparing the MMP and the NMP (Figure 3e). It can be seen from Figure 3e that the mean Young's modulus value of MMP decreases from $6.11 \pm 2.98 \mathrm{MPa}$ to $2.72 \pm 0.86 \mathrm{MPa}$ for CNT concentrations of 0 and $15 \mathrm{mg} / \mathrm{mL}$, respectively. The Young's modulus of NMP, on the contrary, increases from $0.06 \pm 0.02 \mathrm{MPa}$ to $0.64 \pm 0.26 \mathrm{MPa}$ for CNT concentrations of 0 and $15 \mathrm{mg} / \mathrm{mL}$, respectively. The presence of a large number of drop-out points for NMP indicates that when scanning a surface, the cantilever often comes into contact with objects that significantly exceed the average Young's modulus of 
the surface. The number of drop-out points increases upon increasing the concentration of CNTs. This behavior of mechanical properties can be explained by the peculiarities of the measurement. The UTM compresses the sample, therefore, the particles are then embedded in the structure of the hydrogel creating additional disturbances in the integrity of the lattice. At the same time, AFM senses the rigidity of the particles on the surface of the hydrogel, thereby increasing the average Young's modulus. In addition to mechanical mapping, rheology study has been conducted.

Rheology is the study of the flow behavior of a material, under conditions in which they flow rather than elastic or plastic deformation. It is also concerned with establishing predictions for mechanical behavior (on the continuum mechanical scale) based on the micro- or nano-structure of the materials. Both storage and loss moduli are typically measured in rheology studies. Figure $3 \mathrm{f}$ shows the storage modulus and Figure $3 \mathrm{~g}$ presents the loss modulus of GG-CNTs hydrogels as a function of different CNT concentrations. It can be noticed from the storage modulus of nanocomposites gradually increases with an increasing frequency and CNT concentration, indicating a transition from the viscous (liquid) to solid-like behavior.

\subsection{Cells Morphology and Adhesion on the GG-CNTs Hydrogels}

Fluorescence images of samples prepared with $15 \mathrm{mg} / \mathrm{mL}$ CNTs show cells with a lack of the disturbance of the membrane; analysis here has been performed for 1 and 3 days of cell incubation (Figure 4a). It can be seen from Figure 4a that osteoblasts are exhibit sufficient cell adhesion and homogeneous distribution, similar to that of the control sample. On the other hand, hydrogels prepared using 0,5 and $10 \mathrm{mg} / \mathrm{mL}$ of CNTs hosted cells with morphologies atypical for osteoblasts, mostly round. These cells are poorly attached to the gel mesh and exhibit insufficient adhesion to gels while lacking a homogeneous distribution.
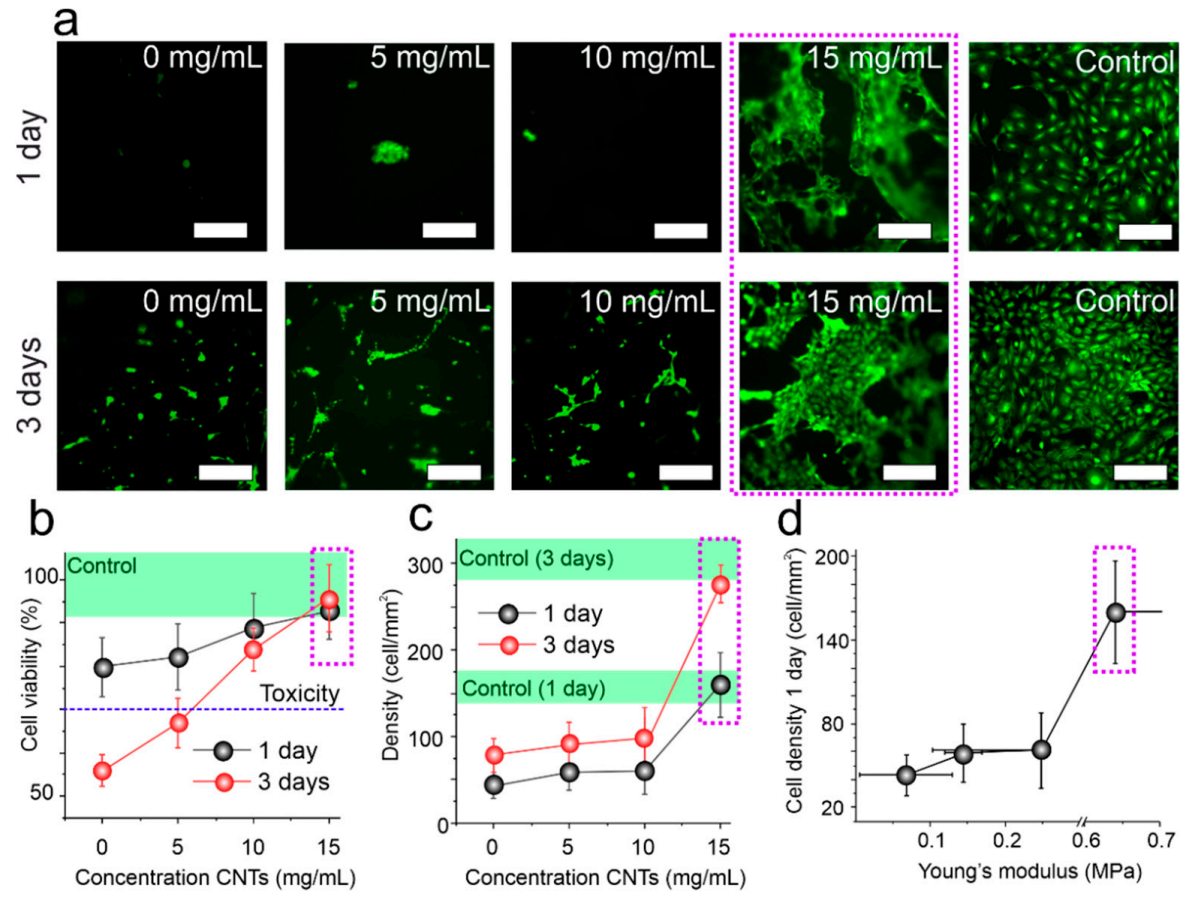

Figure 4. (a) Fluorescence microscopy images of MC3T3-E1 cells on GG-CNTs hydrogels surface. Cells on the the surface of a plastic cell culture dish are present as a control. Scale bars correspond to $250 \mu \mathrm{m}$. (b) Cell viability on GG-CNTs hydrogels as a function of the concentration of CNTs. (c) The number of cells adhered to the surface of the samples after 1 and 3 days of incubation as a function of the concentration of CNTs. (d) Cell density after 1 day of incubation versus Young's modulus of GG-CNTs. 
Tests with Alamar Blue showed the same viability of cells for 1 day of incubation and compared with control (Figure $4 \mathrm{~b}$ ). However, results dramatically changed after three days of incubation. It occurred, because of a good adhesion of cells on the $15 \mathrm{mg} / \mathrm{mL}$ hydrogel which is better than that on other hydrogels. This is essential, because cell survival is highly dependent on cell adhesion. With poor adhesion, a cascade of genes is triggered in osteoblast cells, which leads to cell death $[42,43]$. In this regard, samples are considered toxic if they inhibit more than 30 percent of cell growth relative to control [44].

A study of cell adhesion on the surface of the modified and unmodified hydrogels was also conducted (Figure 4d and Figure S4). This experiment has enabled determination of the number of cells that can be attach after 1 day of incubation on the surface of the tested samples. The largest number of cells $\left(162 \mathrm{cell} / \mathrm{mm}^{2}\right)$ was found to adhere to the surface of $15 \mathrm{mg} / \mathrm{mL}$ GG-GNTs- hydrogel. For 1 day after the incubation, this number of cells does not have a statistical difference compared with the control plastic surface $\left(157 \mathrm{cell} / \mathrm{mm}^{2}\right)$, but it is very different from those of other hydrogels: 43,59 , and $61 \mathrm{cell} / \mathrm{mm}^{2}$ for 0,5 , $10 \mathrm{mg} / \mathrm{mL}$ GG-CNTs hydrogels, respectively. After three days of incubation, the number of cells increased further. Specifically, the number of cells on the $15 \mathrm{mg} / \mathrm{mL}$ sample increased in 1.82 times $\left(277 \pm 23 \mathrm{cell} / \mathrm{mm}^{2}\right)$ and had no statistical differences with the control sample. The number of cells on 0,5 , and $10 \mathrm{mg} / \mathrm{mL}$ GG-CNTs hydrogels ranged from 55 to 96 cell $/ \mathrm{mm}^{2}$. We assume that this is due to the difference in the mechanical properties of the hydrogel and the inorganic CNTs particles. Cells use the rigid CNTs (similarly to the situation with particles) as sites to bind to the substrate. However, the concentration of CNTs must be high enough to provide the cells with the required number of inorganic content (equivalent to particles) to form stable integrin clusters [36]. It is found here that, in this case, this concentration corresponds to $15 \mathrm{mg} / \mathrm{mL}$.

It can be noticed that the cell density at the surface correlates with the surface Young's modulus (Figure 4c). In this case, the low number of cells on GG hydrogels is explained by the lack of bindings sites [45]. At the hydrogel prepared using $15 \mathrm{mg} / \mathrm{mL}$ CNT, a large number of CNTs appear on the surface of the hydrogel, which is sensed by both AFM and cells. CNTs are excellent binding sites for cells, which is in agreement with previously reported data [19].

\section{Conclusions}

In conclusion, a simple method of fabricating composite GG-CNTs hydrogels is developed. The increase of the used concentration of CNTs strengthens hydrogels, at the same time this improves cellular adhesion. Macro- and nano-mechanical properties of the GG-CNTs hydrogels are received by a universal mechanical universal testing machine and AFM. The Young's modulus of NMP increases from $0.06 \pm 0.02 \mathrm{MPa}$ to $0.64 \pm 0.26 \mathrm{MPa}$ for hydrogels made using 0 and $15 \mathrm{mg} / \mathrm{mL} \mathrm{CNT}$, respectively; this is supported by the presence of CNTs on the hydrogel surface. Cells are found to effectively adhere and proliferate on GG-CNTs hydrogels prepared with a minimal concentration of CNT of $15 \mathrm{mg} / \mathrm{mL}$. This study demonstrates a way to turn soft cell repellent GG hydrogels from an unsuitable into an effective cell proliferation platform to cell-adhesive coatings with high potential to be employed in a broad range of applications in cell biology and tissue engineering. The proposed approach of using CNT together with hydrogel is envisioned to enable a myriad of applications, where the hardness of nanotubes would be a desirable feature. Some of them are shown here in the area of biomedical applications, but the full potential of such coatings is expected to be realized in other areas and applications as well.

Supplementary Materials: The following are available online at https:/ / www.mdpi.com/2311-5 629/7/1/18/s1, Figure S1: (a) SEM image of CNTs; Figure S2: (a) Absorbance of the GG-CNTs hydrogels. (b) Photo of the GG-CNTs hydrogels; Figure S3: Swelling coefficient of the GG-CNTs hydrogels; Figure S4: Counted cells. Scalebar is $125 \mu \mathrm{m}$. 
Author Contributions: Synthesis of samples, testing of mechanical properties, experiments with cells, writing-original draft preparation, A.A.; AFM characterization of samples by AFM, L.V.d.M.; characterization of samples by SEM, writing, B.P.; review and editing, D.V. and A.G.S. All authors have read and agreed to the published version of the manuscript.

Funding: This research was supported by the Special Research Fund (BOF) of Ghent University (01IO3618, BAS094-18, BOF14/IOP/003), FWO-Vlaanderen (G043219, I002620N) and by the Russian Science Foundation, grant number 19-73-10123.

Acknowledgments: A.A. thanks the "Global education" program of the Russian government for funding. B.P. thanks FWO (Belgium) for post-doctoral fellowship.

Conflicts of Interest: The authors declare no conflict of interest.

\section{References}

1. Douglas, T.E.L.; Dziadek, M.; Gorodzha, S.; Liskova, J.; Brackman, G.; Vanhoorne, V.; Vervaet, C.; Balcaen, L.; Garcia, M.D.F.; Boccaccini, A.R.; et al. Novel Novel injectable gellan gum hydrogel composites incorporating Zn- and Sr-enriched bioactive glass microparticles: High-resolution X-ray microcomputed tomography, antibacterial and in vitro testing. J. Tissue Eng. Regen. Med. 2018, 12, 1313-1326. [CrossRef] [PubMed]

2. Lee, J.H. Injectable hydrogels delivering therapeutic agents for disease treatment and tissue engineering. Biomater. Res. 2018, 22, 27. [CrossRef] [PubMed]

3. Griffith, L.G.; Naughton, G. Tissue engineering-Current challenges and expanding opportunities. Science 2002, 295. [CrossRef] [PubMed]

4. Ul Malik, Q.A.; Iftikhar, S.; Zahid, S.; Safi, S.Z.; Khan, A.F.; Nawshad, M.; Ghafoor, S.; Khan, A.S.; Tufail Shah, A. Smart injectable self-setting bioceramics for dental applications. Mater. Sci. Eng. C 2020, 113, 110956. [CrossRef]

5. Liu, W.; Sun, J.; Sun, Y.; Xiang, Y.; Yan, Y.; Han, Z.; Bi, W.; Yang, F.; Zhou, Q.; Wang, L.; et al. Multifunctional injectable protein-based hydrogel for bone regeneration. Chem. Eng. J. 2020, 394, 124875. [CrossRef]

6. Guo, F.; Huang, K.; Niu, J.; Kuang, T.; Zheng, Y.; Gu, Z.; Zou, J. Enhanced osseointegration of double network hydrogels via calcium polyphosphate incorporation for bone regeneration. Int. J. Biol. Macromol. 2020, 151, 1126-1132. [CrossRef]

7. Luo, Y.; Shoichet, M.S. A photolabile hydrogel for guided three-dimensional cell growth and migration. Nat. Mater. 2004, 3, 249-254. [CrossRef]

8. Lühmann, T.; Hall, H. Cell guidance by 3D-gradients in hydrogel matrices: Importance for biomedical applications. Materials 2009, 2, 1058. [CrossRef]

9. Abalymov, A.; Van Poelvoorde, L.; Atkin, V.S.; Skirtach, A.G.; Konrad, M.; Parakhonskiy, B. Alkaline phosphatase delivery system based on calcium carbonate carriers for acceleration of ossification. ACS Appl. Bio Mater. 2020, 3, 2986-2996. [CrossRef]

10. Abalymov, A.; Parakhonskiy, B.; Skirtach, A.G. Polymer-and hybrid-based biomaterials for interstitial, connective, vascular, nerve, visceral and musculoskeletal tissue engineering. Polymers 2020, 12, 620. [CrossRef]

11. Saveleva, M.S.; Eftekhari, K.; Abalymov, A.; Douglas, T.E.L.; Volodkin, D.; Parakhonskiy, B.V.; Skirtach, A.G. Hierarchy of hybrid materials-the place of inorganics-in-organics in it, their composition and applications. Front. Chem. 2019, 7, 179. [CrossRef]

12. Vashist, A.; Kaushik, A.; Ghosal, A.; Bala, J.; Nikkhah-Moshaie, R.; Wani, W.A.; Manickam, P.; Nair, M. Nanocomposite hydrogels: Advances in nanofillers used for nanomedicine. Gels 2018, 4, 75. [CrossRef]

13. Zaragoza, J.; Fukuoka, S.; Kraus, M.; Thomin, J.; Asuri, P. Exploring the Role of Nanoparticles in enhancing mechanical properties of hydrogel nanocomposites. Nanomaterials 2018, 8, 882. [CrossRef]

14. Skirtach, A.G.; Volodkin, D.V.; Möhwald, H. Bio-interfaces-Interaction of PLL/HA thick films with nanoparticles and microcapsules. ChemPhysChem 2010, 11, 822-829. [CrossRef]

15. Lengert, E.V.; Koltsov, S.I.; Li, J.; Ermakov, A.V.; Parakhonskiy, B.V.; Skorb, E.V.; Skirtach, A.G. Nanoparticles in polyelectrolyte multilayer Layer-by-Layer (LbL) films and capsules-key enabling components of hybrid coatings. Coatings 2020, $10,1131$. [CrossRef]

16. Baibarac, M.; Gómez-Romero, P. Nanocomposites based on conducting polymers and carbon Nnanotubes: From fancy materials to functional applications. J. Nanosci. Nanotechnol. 2006, 6, 289-302. [CrossRef]

17. Liu, W.; Giorgio, S. Speranza Functionalization of carbon nanomaterials for biomedical applications. C J. Carbon Res. $2019,5,72$. [CrossRef]

18. Yashchenok, A.M.; Bratashov, D.N.; Gorin, D.A.; Lomova, M.V.; Pavlov, A.M.; Sapelkin, A.V.; Shim, B.S.; Khomutov, G.B.; Kotov, N.A.; Sukhorukov, G.B.; et al. Carbon nanotubes on polymeric microcapsules: Free-standing structures and point-wise laser openings. Adv. Funct. Mater. 2010, 20, 3136-3142. [CrossRef]

19. Vashist, A.; Kaushik, A.; Vashist, A.; Sagar, V.; Ghosal, A.; Gupta, Y.K.; Ahmad, S.; Nair, M. Advances in carbon nanotubeshydrogel hybrids in nanomedicine for therapeutics. Adv. Healthc. Mater. 2018, 7, 1701213. [CrossRef] [PubMed]

20. Kaiser, J.-P.; Buerki-Thurnherr, T.; Wick, P. Influence of single walled carbon nanotubes at subtoxical concentrations on cell adhesion and other cell parameters of human epithelial cells. J. King Saud Univ. Sci. 2013, 25, 15-27. [CrossRef]

21. Tilmaciu, C.-M.; Morris, M.C. Carbon nanotube biosensors. Front. Chem. 2015, 3. [CrossRef] 
22. Barinov, A.; Gregoratti, L.; Dudin, P.; La Rosa, S.; Kiskinova, M. Imaging and spectroscopy of multiwalled carbon nanotubes during oxidation: Defects and oxygen bonding. Adv. Mater. 2009, 21, 1916-1920. [CrossRef]

23. Saleh, T.A. The influence of treatment temperature on the acidity of MWCNT oxidized by $\mathrm{HNO} 3$ or a mixture of $\mathrm{HNO} 3 / \mathrm{H} 2 \mathrm{SO} 4$. Appl. Surf. Sci. 2011, 257, 7746-7751. [CrossRef]

24. Hiura, H.; Ebbesen, T.W.; Tanigaki, K. Opening and purification of carbon nanotubes in high yields. Adv. Mater. 1995, 7, 275-276. [CrossRef]

25. Chiang, Y.-C.; Lin, W.-H.; Chang, Y.-C. The influence of treatment duration on multi-walled carbon nanotubes functionalized by H2SO4/HNO3 oxidation. Appl. Surf. Sci. 2011, 257, 2401-2410. [CrossRef]

26. Heller, D.A.; Jena, P.V.; Pasquali, M.; Kostarelos, K.; Delogu, L.G.; Meidl, R.E.; Rotkin, S.V.; Scheinberg, D.A.; Schwartz, R.E.; Terrones, M.; et al. Banning carbon nanotubes would be scientifically unjustified and damaging to innovation. Nat. Nanotechnol. 2020, 15, 164-166. [CrossRef] [PubMed]

27. Hernández-González, A.C.; Téllez-Jurado, L.; Rodríguez-Lorenzob, L.M. Synthesis of in-sity silica alginate hybrid hydrogels by sol-gel route. Carbohydr. Polym. 2020, 250, 116877. [CrossRef]

28. Volodkin, D.V.; Delcea, M.; Mohwald, H.; Skirtach, A.G. Remote near-IR light activation of a hyalyronic acid/poly-L-lysine multilayred film and film-entrapped microcapsules. ACS Appl. Mater. Interfaces 2009, 1, 1705-1710. [CrossRef]

29. Killion, J.A.; Kehoe, S.; Geever, L.M.; Devine, D.M.; Sheehan, E.; Boyd, D.; Higginbotham, C.L. Hydrogel/bioactive glass composites for bone regeneration applications: Synthesis and characterisation. Mater. Sci. Eng. C 2013, 33, 4203-4212. [CrossRef] [PubMed]

30. Bendtsen, S.T.; Quinnell, S.P.; Wei, M. Development of a novel alginate-polyvinyl alcohol-hydroxyapatite hydrogel for 3D bioprinting bone tissue engineered scaffolds. J. Biomed. Mater. Res. Part A 2017, 105, 1457-1468. [CrossRef]

31. Manda, M.G.; da Silva, L.P.; Cerqueira, M.T.; Pereira, D.R.; Oliveira, M.B.; Mano, J.F.; Marques, A.P.; Oliveira, J.M.; Correlo, V.M.; Reis, R.L. Gellan gum-hydroxyapatite composite spongy-like hydrogels for bone tissue engineering. J. Biomed. Mater. Res. Part A 2018, 106, 479-490. [CrossRef]

32. Abalymov, A.; Van der Meeren, L.; Skirtach, A.G.; Parakhonskiy, B.V. Identification and analysis of key parameters for the ossification on particle functionalized composites hydrogel materials. ACS Appl. Mater. Interfaces 2020. [CrossRef] [PubMed]

33. Abalymov, A.; Van der Meeren, L.; Saveleva, M.; Prikhozhdenko, E.; Dewettinck, K.; Parakhonskiy, B.; Skirtach, A.G. Cells-grab-on particles: A novel approach to control cell focal adhesion on hybrid thermally annealed hydrogels. ACS Biomater. Sci. Eng. 2020. [CrossRef]

34. Schröder, R.; Pohlit, H.; Schüler, T.; Panthöfer, M.; Unger, R.E.; Frey, H.; Tremel, W. Transformation of vaterite nanoparticles to hydroxycarbonate apatite in a hydrogel scaffold: Relevance to bone formation. J. Mater. Chem. B 2015, 3, 7079-7089. [CrossRef] [PubMed]

35. Parakhonskiy, B.V.; Abalymov, A.; Ivanova, A.; Khalenkow, D.; Skirtach, A.G. Magnetic and silver nanoparticle functionalized calcium carbonate particles-Dual functionality of versatile, movable delivery carriers which can surface-enhance Raman signals. J. Appl. Phys. 2019, 126, 203102. [CrossRef]

36. Abalymov, A.A.; Parakhonskiy, B.V.; Skirtach, A.G. Colloids-at-surfaces: Physicochemical approaches for facilitating cell adhesion on hybrid hydrogels. Colloids Surfaces A Physicochem. Eng. Asp. 2020, 603, 125185. [CrossRef]

37. Douglas, T.E.L.; Kumari, S.; Dziadek, K.; Dziadek, M.; Abalymov, A.; Cools, P.; Brackman, G.; Coenye, T.; Morent, R.; Mohan, M.K.; et al. Titanium surface functionalization with coatings of chitosan and polyphenol-rich plant extracts. Mater. Lett. 2017, 196, 213-216. [CrossRef]

38. Imaninezhad, M.; Schober, J.; Griggs, D.; Ruminski, P.; Kuljanishvili, I.; Zustiak, S.P. Cell Attachment and spreading on carbon nanotubes is facilitated by integrin binding. Front. Bioeng. Biotechnol. 2018, 6. [CrossRef]

39. Jansen, R.; Wallis, P. Manufacturing, Characterization and use of single walled carbon nanotubes. Mater. Matters $2009,4,23$.

40. Van der Meeren, L.; Verduijn, J.; Krysko, D.V.; Skirtach, A.G. AFM Analysis enables differentiation between apoptosis, necroptosis, and ferroptosis in murine cancer cells. iScience 2020, 23, 101816. [CrossRef]

41. Sollich, P.; Lequeux, F.; Hébraud, P.; Cates, M.E. Rheology of soft glassy materials. Phys. Rev. Lett. 1997, 78, 2020-2023. [CrossRef]

42. Rozario, T.; DeSimone, D.W. The extracellular matrix in development and morphogenesis: A dynamic view. Dev. Biol. 2010, 341, 126-140. [CrossRef]

43. Hussey, G.S.; Dziki, J.L.; Badylak, S.F. Extracellular matrix-based materials for regenerative medicine. Nat. Rev. Mater. 2018, 3, 159-173. [CrossRef]

44. CSA. ISO 10993-5 In vitro cytotox. Int. Organ. 2009, 2007, 1-11. [CrossRef]

45. Bacelar, A.H.; Silva-Correia, J.; Oliveira, J.M.; Reis, R.L. Recent progress in gellan gum hydrogels provided by functionalization strategies. J. Mater. Chem. B 2016, 4, 6164-6174. [CrossRef] [PubMed] 